\title{
Tiotropium - advancing the treatment of COPD
}

\author{
Scott Chambers \\ CSF Medical Communications, Cheltenham, UK
}

\section{This manuscript was peer-reviewed by:}

Michael Schachter, Senior Lecturer, Department of Clinical Pharmacology, National Heart and Lung Institute, Imperial College School of Medicine, London, UK

Professor David Price, University of Aberdeen, Aberdeen, UK

\section{EDITORIAL BOARD}

Editor in Chief: George Kassianos, GP, Bracknell, Berkshire, UK. Editorial Executive Committee: Allan Gaw, Director, Clinical Trials Unit, Glasgow Royal Infirmary, Glasgow, UK; Professor Michael Kirby, University of Hertfordshire, Hatfield, Hertfordshire, UK; fonathan Morrell, GP and Hospital Practitioner, Hastings, East Sussex, UK; Michael Schachter, Senior Lecturer, Department of Clinical Pharmacology, National Heart and Lung Institute, Imperial College School of Medicine, London, UK; Editors: Professor Fuan Tamargo, School of Medicine, Universidad Complutense, Madrid, Spain; Barbara Yawn, Director of Research, Olmsted Medical Center, Rochester, Minnesota, USA; Roy Yawn, Chair of Internal Medicine, Olmsted Medical Center, Rochester, Minnesota, USA; Editorial Advisory Board: Khalid Barakat, Consultant Cardiologist, Heatherwood and Wexham Hospitals NHS Trust, Berkshire, UK; Pam Brown, GP, Uplands, Swansea, UK; Famie Dalrymple, GP, Norwich, Norfolk, UK; Kurt Elward, Family Physician, Charlottesville, Virginia, USA; Professor Ted Ganiats, University of California, San Diego, California, USA; David Halpin, Consultant Physician, Royal Devon and Exeter Hospital, Exeter, Devon, UK; Professor Mike LeFevre, University of Missouri, St Louis, Missouri, USA; Frederick North, Physician, Department of Internal Medicine, Mayo Clinic, Rochester, Minnesota, USA; Professor David Price, University of Aberdeen, Aberdeen, UK; fill Rasmussen, GP, Merstham, Surrey, UK; Professor Steven Spann, Baylor School of Medicine, Houston, Texas, USA; Richard Stevens, GP, Oxford, Oxfordshire, UK; Professor Alfred F. Tallia, University of Medicine and Dentistry, New Jersey, USA; Professor Don Uden, University of Minnesota, Minnesota, USA; Marion Waite, Senior Lecturer in Primary Care, Oxford Brookes University, Oxford, UK; Derek Waller, Consultant Physician, Southampton General Hospital, Southampton, UK.

Search criteria: English language articles were identified by searching the PubMed database using the search terms 'tiotropium', 'COPD' and 'chronic obstructive pulmonary disease'. Abstracts were evaluated and selected for further review according to our standard protocols. Bibliographies of individual articles were also assessed for additional articles of interest and the manufacturer of tiotropium was contacted and was invited to supply any additional data to that identified via the PubMed database. Date of last literature search: 20 October 2007

Conclusion: Tiotropium is a first-line choice for the management of patients with COPD whose symptoms are not adequately controlled by as-needed short-acting bronchodilators. It is currently the only long-acting inhaled anticholinergic bronchodilator available for the maintenance treatment of COPD and its introduction has heralded an important advance in the management of this devastating disease. 


\section{SUMMARY}

Inhaled anticholinergic bronchodilators are a treatment of choice for chronic obstructive pulmonary disease (COPD). Tiotropium is currently the only long-acting inhaled anticholinergic bronchodilator available and works by selectively inhibiting muscarinic receptors involved in mucus hypersecretion and bronchoconstriction, two characteristic features of COPD. Clinical trials have demonstrated the efficacy of tiotropium across all degrees of severity of stable COPD. Tiotropium improves airway function, symptoms of dyspnoea, exercise endurance and health status. Treatment with tiotropium also reduces acute exacerbations associated with COPD as well as associated hospitalisations. The clinical improvements observed with tiotropium are associated with changes in airway volume, particularly inspiratory capacity, which translate into improvements in patient-centred outcomes, such as breathlessness during exercise. Emerging evidence indicates that tiotropium may exert additive effects when used in combination with the long-acting $\beta_{2}$-agonist (LABA), formoterol, consistent with the current recommendations for combination therapy in patients who do not respond to a single bronchodilator. Encouraging results have also been obtained with tiotropium in triple combination with salmeterol/fluticasone propionate. Furthermore, post hoc analyses suggest that tiotropium may slow the rate of decline in lung function characteristic of COPD. Recent studies indicate that combining tiotropium therapy with pulmonary rehabilitation programmes can yield significant improvements in exercise endurance time. In safety evaluations, tiotropium was generally well tolerated with a similar safety profile to ipratropium, a short-acting anticholinergic bronchodilator. Dry mouth is the most common adverse event reported with tiotropium, although this is generally transient and does not lead to treatment discontinuation.

Key words: Chronic obstructive pulmonary disease; COPD; anticholinergic; tiotropium; Spiriva.

\section{COPD: A PERSPECTIVE}

COPD is a common condition caused by longterm exposure to environmental pollutants, particularly tobacco smoke. COPD is associated with an enormous burden of mortality and morbidity and has huge socioeconomic implications. According to estimates from the World Health Organization, about 80 million people are living with moderate-to-severe COPD across the globe. Amongst non-infectious chronic diseases, COPD is the only cause of death that is on the increase. ${ }^{1,2}$ In 2005, more than 3 million people died of COPD, corresponding to about $5 \%$ of all deaths globally, establishing it as the fifth leading cause of mortality. However, total deaths from COPD are projected to increase by more than $30 \%$ over the next 10 years, with estimates showing that COPD will become the fourth leading cause of death worldwide by $2030 .^{3}$

The primary objectives of COPD management are to improve patients' symptoms, reduce the decline in lung function, improve quality of life and reduce disease exacerbations and hospitalisations. ${ }^{4}$ Smoking cessation is the most important intervention and can slow the progressive decline in lung function in patients with established disease. Pulmonary rehabilitation programmes, which provide exercise training, education and support, are also becoming increasingly recognised as an effective management strategy for COPD. Pharmacological interventions, including inhaled bronchodilators and corticosteroids, are central to the management of patients with COPD and can improve lung function, symptoms, quality of life and reduce disease exacerbations.

Bronchoconstriction and mucus hyper secretion, two fundamental features of COPD, are regulated by the autonomic nervous system. The neurotransmitter involved in both processes is acetylcholine, and its effects are mediated via muscarinic receptors. The $\mathrm{M}_{1}$ and $\mathrm{M}_{3}$ receptors 
mediate bronchoconstriction and stimulate mucus secretion whilst $\mathrm{M}_{2}$ controls the release of acetylcholine from $\mathrm{M}_{1}$ and $\mathrm{M}_{3}$ receptors through a negative feedback mechanism. ${ }^{5}$ Anticholinergic bronchodilators (e.g. ipratropium and tiotropium) act by blocking the action of acetylcholine at muscarinic receptors and induce relaxation of airway smooth muscle. Ipratropium is limited by a relatively short duration of action (4-6 hours) and by its non-selective binding to the $\mathrm{M}_{2}$ receptor, which may increase acetylcholine release and thus overcome the blockade of muscarinic receptors in bronchial muscle. Tiotropium is the most recent anticholinergic bronchodilator to be introduced and exhibits long-lasting 'kinetic selectivity' for the $\mathrm{M}_{1}$ and $\mathrm{M}_{3}$ receptors over $\mathrm{M}_{2}$ receptors, a property which translates into an extended duration of action without the undesirable effect of increased acetylcholine production. ${ }^{6}$

\section{PHARMACOLOGY}

\section{Muscarinic receptor selectivity}

Bronchoconstriction and mucus hypersecretion are mediated by the binding of acetylcholine to muscarinic receptors. Tiotropium binds to the $\mathrm{M}_{1}, \mathrm{M}_{2}$ and $\mathrm{M}_{3}$ muscarinic receptors with subnanomolar affinities, with up to 10-times greater potency than ipratropium. ${ }^{7,8}$ Furthermore, compared with ipratropium, tiotropium dissociates over 100-times more slowly from the $\mathrm{M}_{1}$ and $\mathrm{M}_{3}$ receptors and thus exerts a longer lasting inhibitory effect on these receptor subtypes. Tiotropium also dissociates more rapidly from the $\mathrm{M}_{2}$ receptor than from the $\mathrm{M}_{1}$ and $\mathrm{M}_{3}$ receptors. ${ }^{7}$ These factors maximise the bronchodilatory effects of the drug and minimise the increased release of acetylcholine mediated through the $\mathrm{M}_{2}$ receptor.

\section{Pharmacokinetics}

After inhalation, plasma concentrations of tiotropium remain low as a consequence of minimal absorption from the respiratory mucosa. Approximately $20 \%$ of an inhaled dose is deposited in the lungs. Peak plasma concentrations are reached within 5 minutes and then decline rapidly within 1 hour. The terminal half-life of the drug is 5-6 days. ${ }^{9}$ There is no evidence of accumulation with repeated administration. ${ }^{10}$ As tiotropium is excreted primarily through the kidney, renal impairment can increase plasma concentrations of the drug, and consequently tiotropium should only be used in patients with moderate-to-severe renal impairment if the benefits outweigh the potential risks. ${ }^{11,12}$

\section{CLINICAL EFFICACY}

\section{Endpoint selection}

Most clinical trials of pharmacotherapy for COPD assess improvements in spirometric measures of lung function (e.g. forced expiratory volume in 1 second $\left[\mathrm{FEV}_{1}\right]$, forced vital capacity [FVG] and peak expiratory flow rate [PEFR]). ${ }^{13}$ However, these measures correlate poorly with patients' symptoms and quality of life and therefore other measures of efficacy should be evaluated to determine the impact of drug treatment on the clinical course of the disease. ${ }^{14}$ Such measures include exercise tolerance, symptom relief, rescue medication usage, prevention of exacerbations and hospitalisations, and improvements in quality of life. ${ }^{13}$

\section{Placebo-controlled trials}

\section{Short-term studies}

Initial evidence supporting the efficacy of tiotropium in moderate-to-severe stable COPD came from an interim report of a year long double-blind, placebo-controlled clinical trial. ${ }^{15} \mathrm{~A}$ total of 470 patients with moderate-to-severe stable COPD received tiotropium, $18 \mu \mathrm{g}$, or placebo, once daily via a dry-powder inhaler (DPI) for 13 weeks. Patients also received additional therapy as required. Tiotropium treatment was associated with a significant 
improvement in trough $\mathrm{FEV}_{1}$ and $\mathrm{FVC}$, which averaged $12 \%$ above baseline by day 8 and was maintained on days 50 and 92. All tiotropiumrelated improvements in $\mathrm{FEV}_{1}$ and $\mathrm{FVG}$ were significantly superior compared with placebo $(p<0.001$ for all comparisons). Morning and evening PEFR improved with tiotropium compared with placebo $(p<0.05$ for 10 of the 13 weeks), whilst the use of rescue salbutamol fell by $30 \%$ within the first week and was significantly different from placebo at all time points $(p<0.001)$. Tiotropium treatment was also associated with improvements in the physician global assessment $(p<0.001)$ and a reduction in symptoms of wheezing and shortness of breath $(p<0.01)$.

The SPRUCE study - SPiRiva Usual CarE was a 12-week, 44-centre study investigating tiotropium in a population with COPD representative of those seen in primary care. ${ }^{16} \mathrm{Of}$ the 374 patients enrolled, 48\% had mild COPD $\left(\mathrm{FEV}_{1} \geq 50 \%\right.$ predicted, following the classification of COPD advocated by the National Institute for Health and Clinical Excellence [NICE], ${ }^{17}$ and $3 \%$ had severe COPD $\left(\mathrm{FEV}_{1}<30 \%\right.$ predicted $)$. Patients were randomised to tiotropium, $18 \mu \mathrm{g}$ inhaled once daily, or placebo, in addition to usual medication. At baseline, $63 \%$ of patients were using inhaled corticosteroid, 29\% were using long-acting $\beta$ agonists (LABA) and 25\% were using LABA plus inhaled corticosteroid. Tiotropium was associated with a significantly greater improvement in trough $\mathrm{FEV}_{1}$ than that achieved with placebo across all patients (treatment effect was $0.06 \mathrm{~L}, p=0.0102)$. The median improvement in FVC with tiotropium above that achieved with placebo at weeks 2, 6 and 12 was $0.12 \mathrm{~L}(p<0.001)$. Subgroup analysis of patients with mild COPD showed a trend towards improved $\mathrm{FEV}_{1}$ response with titropium, but this did not reach statistical significance. The difference in FVC in patients with mild COPD was small, but did reach significance $(0.08 \mathrm{~L}$ at day $85, p<0.05)$. The use of rescue short-acting $\beta$-agonists was significantly reduced in the group receiving tiotropium compared with the placebo group.

\section{Long-term studies}

The long-term efficacy of tiotropium was investigated in a year-long, randomised, double blind, placebo-controlled study of 921 patients with stable COPD. Patients were randomised to inhaled tiotropium, $18 \mu \mathrm{g}$ once daily, or placebo, over a 1-year period. ${ }^{18}$ Tiotropium led to sustained improvements in patients' lung function compared with placebo, as demonstrated by a trough $\mathrm{FEV}_{1}$ response $(\sim 12 \%$ improvement from baseline; $p<0.01$ at all time points) and a mean $\mathrm{FEV}_{1}$ response during the 3 hours following dosing ( $\sim 22 \%$ improvement over baseline; $p<0.001$ at all time points). No tachyphylaxis was observed for the bronchodilatory effect. Compared with placebo, tiotropium also improved PEFR $(p<0.05$ at all time points) and reported less dyspnoea $(p<0.001$ at all time points), superior health status $(p<0.05)$, fewer exacerbations $(20 \%$ reduction; $p<0.05)$ and fewer hospitalisations $(41 \%$ reduction; $p<0.05)$. Tiotropium also significantly improved shortness of breath and wheezing $(p<0.05)$.

Smoking cessation is widely accepted as the only intervention that can alter the natural course of COPD. However, emerging evidence suggests that pharmacotherapy may also reduce the progressive decline in lung function that characterises COPD. ${ }^{19}$ An important post hoc analysis of the above study has evaluated the effects of long-term tiotropium therapy on the accelerated rate of decline in lung function in COPD patients. ${ }^{20}$ This analysis reported that the mean annual decline in trough $\mathrm{FEV}_{1}$ was 58 and $12 \mathrm{~mL} /$ year in the placebo and tiotropium groups, respectively ( $p=0.005$ vs placebo). The corresponding decline in $\mathrm{FEV}_{1}$ from 6 weeks to 1 year was 59 and $19 \mathrm{~mL} /$ year $(p=0.036$ os placebo). Thus, long-term tiotropium treatment was associated with a reduced rate of decline in 
lung function compared with patients treated with placebo (Figure 1).

\section{Comparative clinical studies}

Tiotropium vs ipratropium

Tiotropium was compared with the short-acting anticholinergic, ipratropium, in a 13-week study of 288 patients with stable COPD. ${ }^{21}$ Patients received either tiotropium, $18 \mu \mathrm{g}$ once daily administered via a DPI, or ipratropium, $40 \mu \mathrm{g}$ four-times daily via metered-dose inhaler (MDI). By day 8, the mean increase in trough $\mathrm{FEV}_{1}$ over baseline was $13 \%$ for tiotropium, an increase which was maintained on days 50 and 92. Moreover, compared with ipratropium, tiotropium produced significantly greater improvements in trough, average and peak $\mathrm{FEV}_{1}$ values (Figure 2), and in trough and average FVC values $(p<0.05$ for all comparisons). Weekly mean morning and evening PEFR was also significantly improved by a greater extent with tiotropium than with ipratropium $(p<0.05)$, and patients receiving tiotropium also required less rescue salbutamol $(p<0.05)$.

In a randomised, double-blind, comparative study, 535 patients were randomised to either tiotropium, $18 \mu \mathrm{g}$ once daily from a DPI, or ipratropium, $40 \mu \mathrm{g}$ four-times daily from an
Figure 2. Mean forced expiratory volume in 1 second $\left(\mathrm{FEV}_{1}\right)$ values before and 6 hours after inhalation of tiotropium or ipratropium in patients with stable chronic obstructive pulmonary disease. ${ }^{21}$ Data shown are for the final study evaluation on day 92 .

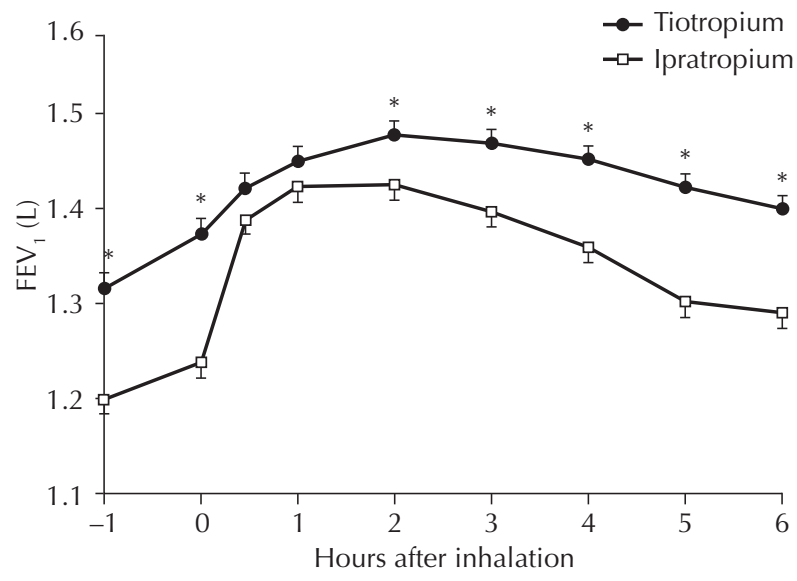

${ }^{*} p<0.05$ for tiotropium vs ipratropium

MDI, for 1 year. ${ }^{22}$ Tiotropium produced significantly greater improvements in lung function, exacerbations and health-related quality of life. Thus, trough $\mathrm{FEV}_{1}$ at 1 year increased by $0.12 \pm 0.01 \mathrm{~L}$ with tiotropium but fell by $0.03 \pm 0.02 \mathrm{~L}$ with ipratropium $(p<0.001)$. Compared with ipratropium, tiotropium elicited a significant improvement in PEFR $(p<0.01$ at all time points), dyspnoea ( $p<0.05$ at all time points),

Figure 1. Decline in trough forced expiratory volume in 1 second $\left(\mathrm{FEV}_{1}\right)$ with tiotropium and placebo from days 8 to 344 (left) and from days 50 to 344 (right). ${ }^{20}$

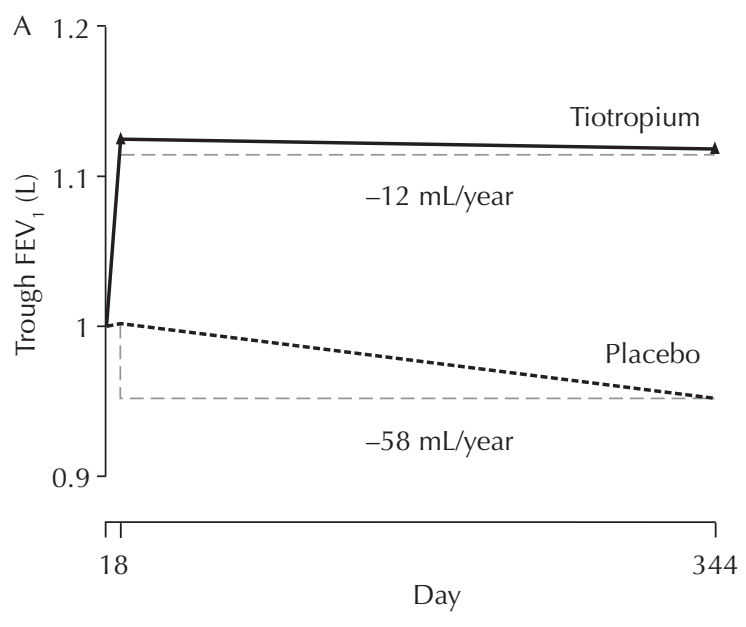

$p=0.05$ tiotropium $v s$ placebo

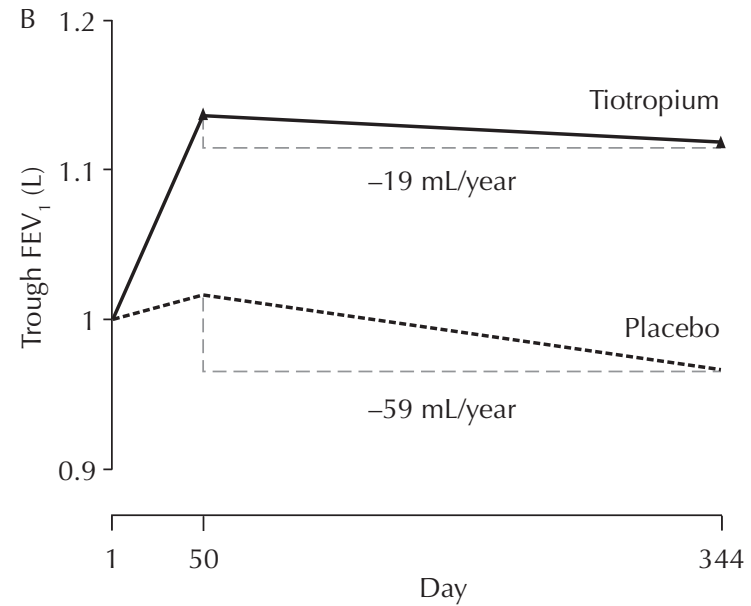

$p=0.036$ tiotropium vs placebo 
health status scores $(p<0.05$ on day 364), the number of exacerbations (reduced by $24 \%$; $p<0.01)$, the time to first exacerbation $(p<0.01)$, the time to first hospitalisation for an exacerbation $(p<0.05)$ and rescue salbutamol use $(p<0.05$ for 40 of the 52 weeks).

\section{Tiotropium vs LABAs}

\section{Tiotropium vs salmeterol}

The efficacy of tiotropium has been compared with salmeterol in a randomised, double-blind, placebo-controlled trial. ${ }^{23} \mathrm{~A}$ total of 623 patients received placebo, tiotropium, $18 \mu \mathrm{g}$ once daily via DPI, or salmeterol, $50 \mu \mathrm{g}$ twice daily via MDI. After 6 months' treatment, the mean pre-dose morning $\mathrm{FEV}_{\text {, was }}$ higher in patients receiving tiotropium $(0.14 \mathrm{~L})$ than in those who received salmeterol (0.09 L; $p<0.01)$, whilst the average $\mathrm{FEV}_{1}$ over a 12-hour assessment was also higher (between-group difference $0.08 \mathrm{~L} ; p<0.001$ ). Both active treatments were superior to placebo in improving weekly mean morning and evening PEFR ( $p<0.001$ for all comparisons), with no significant difference between active treatments for these parameters. Dyspnoea improved more with tiotropium compared with both placebo $(p=0.01)$ and salmeterol $(p<0.05)$, with salmeterol having no significant effect $(p=0.56)$. Both tiotropium and salmeterol reduced the need for rescue salbutamol therapy (both $p<0.0001$ vs placebo), although only tiotropium significantly improved patients' health status $(p<0.05$ vs placebo). Fewer patients experienced exacerbations with tiotropium than with salmeterol, although this difference did not reach statistical significance. ${ }^{24}$ The advantages of tiotropium over salmeterol in lung function were corroborated in a more a recent study of 653 patients. ${ }^{25}$ Thus, after 12 weeks' treatment, the average post-dose $\mathrm{FEV}$, recorded over 12 hours was significantly higher with tiotropium than with salmeterol (167 vs $130 \mathrm{~mL} ; p=0.03$ ) as was peak $\mathrm{FEV}_{1}$ (262 us $216 \mathrm{~mL}$, respectively; $p=0.01$ [Figure 3]). Average $\mathrm{FEV}_{1}$ responses from 0 to 6 hours and from 6 to 12 hours were also higher with tiotropium compared with salmeterol $(p<0.01)$.

COPD exacerbations and healthcare consumption were significantly reduced with tiotropium compared with salmeterol in a pooled analysis of data from the study described

Figure 3. Mean forced expiratory volume in 1 second $\left(\mathrm{FEV}_{1}\right)$ over 12 hours after 12 weeks' treatment with tiotropium and salmeterol. ${ }^{25}$

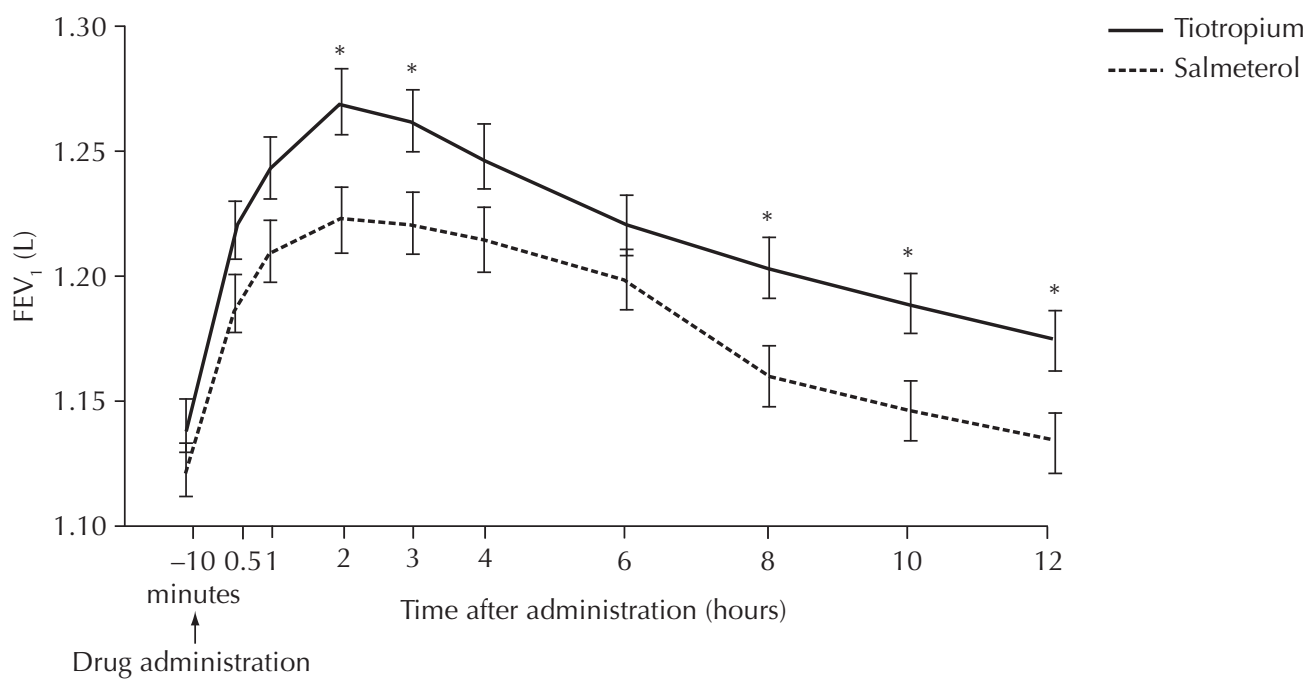


previously $^{23}$ and an identical 6-month study. ${ }^{26}$ Thus, tiotropium, but not salmeterol, significantly delayed the time to first exacerbation compared with placebo $(p \leq 0.01)$. In addition, tiotropium also reduced the incidence of COPD exacerbations compared with both placebo and salmeterol (1.07, 1.49 and 1.23 exacerbations per patient year, respectively; $p=0.025$ for tiotropium vs placebo; $p>0.05$ for salmeterol vs placebo). Although hospital admissions for COPD exacerbations did not significantly differ between the treatment groups, treatment with both tiotropium and salmeterol resulted in fewer days in hospital than placebo $(p<0.05)$. Patients receiving tiotropium also experienced fewer days where their usual daily activities were severely compromised compared with those who received placebo $(p<0.05)$. Finally, tiotropium was also associated with improvements in health-related quality of life, dyspnoea and lung function.

\section{Tiotropium vs formoterol}

A crossover study compared the bronchodilatory effects of tiotropium and the LABA, formoterol, as maintenance therapy for COPD. ${ }^{27}$ The combination of both bronchodilators was also evaluated. A total of 71 patients with moderate-tosevere COPD were randomised to treatment with one of three regimens for three consecutive 6-week treatment periods: tiotropium, $18 \mu \mathrm{g}$ once daily; formoterol, $12 \mu \mathrm{g}$ twice daily; or once-daily combination therapy with both drugs. Compared with formoterol, tiotropium was associated with significantly greater improvements in average daytime $\mathrm{FEV}_{1}(127$ vs $86 \mathrm{~mL} ; p<0.03)$, although night-time $\mathrm{FEV}_{1}$ values did not differ between the two groups ( 43 vs $38 \mathrm{~mL} ; p=0.77$ ). The greatest improvements in $\mathrm{FEV}_{1}$ were seen in the tiotropium/formoterol combination group (234 $\mathrm{mL}$ and $86 \mathrm{~mL}$ for day and night-time $\mathrm{FEV}_{1}$, respectively), which were statistically significant in favour of the combination regimen when compared with either agent given as monotherapy. The effects on lung function in the combination group were also additive. Similar trends were also reported in terms of FVC. A reduced requirement for rescue salbutamol use was reported amongst recipients of the combination compared with those who received either inhaled drug as monotherapy. No additional safety concerns arose when tiotropium and formoterol were coadministered. These data support the current recommendations that a combination of two longacting bronchodilators with distinct mechanisms of action should be considered when treating patients with moderate-to-severe stable COPD.

\section{Tiotropium vs combination treatment}

The INSPIRE study - Investigating New Standards for Prophylaxis in Reduction of Exacerbations - compared the effects of tiotropium, $18 \mu \mathrm{g}$ once daily with those of salmeterol, $50 \mu \mathrm{g} /$ fluticasone propionate, $500 \mu \mathrm{g}$, in combination (SFG) twice daily, on COPD exacerbations in 1323 patients with severe or very severe COPD. The first results were presented at the European Respiratory Society Annual Congress 2007. The two treatments had a similar impact on the overall rate of exacerbations (defined as exacerbations requiring extra use of healthcare resources): 1.32 in the group receiving tiotropium and 1.28 in the $\mathrm{SFC}$ group. ${ }^{28}$ However, there were differences in the type of exacerbation reported in each group. Exacerbations requiring antibiotics were significantly more common with SFC (relative risk [RR] 1.19, $p=0.028$ ), while exacerbations requiring oral corticosteroids were significantly more common in the tiotropium group (RR 0.81, $p=0.039$ ). The rates of symptombased exacerbations were similar in the two treatment groups.

Patients receiving SFG had better survival and health status and were less likely to withdraw from the study than those receiving tiotropium. ${ }^{29}$ But adverse events were slightly more common in those receiving SFG: $66 \%$ of those in the $\mathrm{SFC}$ group experienced an adverse event compared with $62 \%$ in the tiotropium group, with the most 
common event being exacerbation of COPD symptoms. ${ }^{30}$ The study investigators suggested that some of the differences favouring SFC could be attributed to the anti-inflammatory properties of this combination.

\section{Tiotropium in combination}

A small-scale, randomised double-blind crossover study involving 41 patients with COPD compared the effects of tiotropium, $18 \mu \mathrm{g}$ once daily, plus salmeterol, $50 \mu \mathrm{g} /$ fluticasone propionate, $500 \mu \mathrm{g}$, with the effects of each drug taken individually. ${ }^{31}$ Triple therapy significantly improved trough $\mathrm{FEV}_{1}$ compared with tiotropium alone $(212 \mathrm{~mL}, p<0.001)$ and $\mathrm{SFC}$ alone $(110 \mathrm{~mL}, p=0.017)$ on day 14 . Triple therapy was also associated with significantly improved measurements of inspiratory capacity compared with individual components. Patients receiving triple therapy had clinically relevant improvements in transition dyspnoea index (TDI) total score compared with tiotropium alone (2.2, $p<0.001)$, but not compared with SFG alone (0.7; non-significant). Rescue medication was used less often by patients taking the triple combination: 1.0 occasion fewer per day than patients taking tiotropium only $(p<0.001)$, and 0.6 occasions fewer per day than patients taking SFC ( $p=0.01)$.

The Canadian Optimal Therapy of COPD Trial randomly assigned 449 adults with moderate or severe COPD to receive tiotropium and placebo, tiotropium and salmeterol, or tiotropium and SFC for 1 year. ${ }^{32}$ There were no differences in the proportion of patients who experienced an exacerbation between the groups: tiotropium plus placebo, $62.8 \%$; tiotropium plus salmeterol group, 64.8\%; tiotropium plus SFC group, $60.0 \%$. Triple therapy with tiotropium plus SFC improved lung function $(p=0.049)$ and disease-specific quality of life $(p=0.01)$ and reduced the number of hospitalizations for COPD exacerbation (incidence rate ratio, 0.53 [CI, 0.33 to 0.86$]$ ) and all-cause hospitalisations (incidence rate ratio, 0.67 [CI, 0.45 to 0.99]) compared with tiotropium plus placebo. Tiotropium plus salmeterol did not statistically improve lung function or hospitalization rates compared with tiotropium plus placebo.

In the SPRUCE study, the proportion of patients on LABAs with inhaled corticosteroid was higher than expected, leading the authors to speculate on a possible influence on outcomes. ${ }^{16}$ Although the additional bronchodilatatory effect of tiotropium when added to LABAs could not be formally assessed because of the high numbers of patients taking LABA plus inhaled corticosteroid, the authors noted that the response to tiotropium was maintained with concomitant LABA with or without inhaled corticosteroid, supporting the findings of the Canadian study and those of the formoterol crossover study described earlier.

\section{Meta-analyses}

A meta-analysis of 14 large double-blind, randomised clinical trials of long-acting bronchodilators (i.e. salmeterol, formoterol and tiotropium) examined their relative efficacy in the management of COPD within the framework of treatment goals outlined in published guidelines. ${ }^{33}$ Although all agents were considered effective in improving lung function compared with placebo, some significant differences emerged in their relative effects on outcomes other than bronchodilation. Tiotropium provided most consistent and reproducible improvements across these outcomes. These differences may reflect mechanistic differences between the different classes of agents or may relate to tiotropium's duration of action.

A further systematic review recently evaluated data from nine randomised controlled trials $(\mathrm{n}=6,584)$ in an effort to determine the relative efficacy of tiotropium and other bronchodilators with regard to outcomes such as disease exacerbations and hospitalisations, symptoms and 
lung function. ${ }^{34}$ Compared with either placebo or ipratropium, tiotropium reduced the odds of an exacerbation (odds ratio [OR]: 0.74, 95\% confidence interval [CI]: $0.66-0.83)$ and related hospitalisations (OR: 0.64, 95\% CI: 0.51-0.82). From these data, the number needed to treat (NTT) with tiotropium for 1 year to prevent one exacerbation was 14 (95\% CI: 11-22) whilst the NNT to prevent one hospitalisation was 30 (95\% CI: 22-61). However, the reductions in these endpoints did not significantly differ from those afforded by LABAs. Similar trends were reported in quality of life and symptom scales. In terms of lung function, tiotropium treatment was associated with significantly larger increases in $\mathrm{FEV}_{1}$ and FVC compared with placebo, ipratropium and both LABAs. Moreover, the annual decline in $\mathrm{FEV}_{1}$ was reportedly less with tiotropium compared with placebo or ipratropium, though no data were available for the long-acting $\beta_{2}$-agonists with regard to this parameter.

\section{Exercise tolerance}

One double-blind, placebo-controlled trial has reported that tiotropium increased patients' inspiratory capacity compared with placebo after 4 weeks' treatment $(p<0.001)$. This is an important observation given that inspiratory capacity has a higher correlation with patientfocused outcomes (e.g. dyspnoea upon exercise) than other markers of pulmonary function, and may reflect reductions in hyperinflation. Tiotropium provided sustained reduction in lung hyperinflation with increases in inspiratory capacity leading to improvements in exertional dyspnoea and exercise tolerance as demonstrated in a double blind, placebo-controlled trial evaluated in 187 patients with COPD. ${ }^{35}$ This was the first large-scale study to employ exercise testing within a clinical trial setting. Patients were randomly assigned to 6 weeks' treatment with once-daily inhaled tiotropium, $18 \mu \mathrm{g}$, or placebo. By the end of the 6 weeks, tiotropium improved measurements of lung volume and air flow, consistent with the earlier tiotropium studies. Tiotropium was associated with increases in inspiratory capacity and decreases in residual volume and functional residual capacity. Exercise duration (determined by constant-load cycle exercise endurance testing at $75 \%$ of patients' maximal work capacity 2.25 hours after drug dosing), was increased by 105 seconds in patients receiving tiotropium compared with placebo, an increase of $21 \% \quad(p<0.02$ vs placebo). Improvements in lung function and exercise tolerance were associated with a reduction in exertional dyspnoea rated by patients on a dyspnoea rating scale (the Borg scale), which was sustained over the duration of the study. A further double-blind, placebo-controlled trial attempted to determine the duration of tiotropium-related improvements in lung hyperinflation, exertional dyspnoea and exercise tolerance. ${ }^{36}$ Six weeks' tiotropium treatment was associated with an improvement in symptom-limited exercise tolerance, which was sustained for up to 8 hours after dosing over the 6-week study period. Again, tiotropium also reduced lung hyperinflation at rest and during exercise, and exertional dyspnoea. Finally, a 12-week study of 100 patients reported significant improvements in inspiratory capacity compared with placebo on days 42 and 84 ( $p<0.05$ for both). Tiotropium increased the mean distance walked during the shuttle walking test by day 42 and day 84 compared with placebo $(p<0.05$ for both comparisons). By the end of the study more patients in the tiotropium group had significant and clinically meaningful improvements in the health-related quality of life (as determined by the St George's Respiratory Questionnaire [SGRQ]).

\section{COPD exacerbations}

COPD exacerbations are relatively common and have significant clinical and economic consequences. Few studies have prospectively evaluated the effect of tiotropium on the frequency 
of exacerbations and the time to first exacerbation. A large US study randomised 1,829 patients with moderate-to-severe COPD to either tiotropium, 18 $\mu \mathrm{g}$ once daily, or placebo, for a period of 6 months. ${ }^{37}$ Patients also received standard care, including home oxygen where indicated and other respiratory medications, and consequently this study reflects standard community practice. Tiotropium significantly reduced the proportion of patients who experienced at least one COPD exacerbation compared with placebo (27.9 vs $32.3 \%$, respectively; $p=0.037$ ). In addition, fewer tiotropium-treated patients were hospitalised as a result of COPD exacerbations, though this difference was only on the borderline of statistical significance ( 7.0 vs $9.5 \% ; p=0.056)$. Analysis of secondary endpoints demonstrated that, compared with placebo, tiotropium lengthened the time to the first disease exacerbation $(p=0.028)$ and reduced healthcare utilisation for exacerbations, including the frequency of hospitalisations $(p=0.047)$, unscheduled clinic visits $(p=0.019)$ and days where antibiotics were required $(p=0.015)$. A further double-blind study of 1 year in duration compared the effects of tiotropium on disease exacerbations and healthcare resource consumption in 1,110 patients with COPD. ${ }^{38}$ Compared with placebo, tiotropium significantly delayed the time to first exacerbation by approximately 100 days, reduced the proportion of patients experiencing more than one exacerbation by $17 \%$, decreased the number of exacerbations by $35 \%$ and exacerbation days by $37 \%$. Tiotropium also decreased healthcare consumption as evidenced by a significant reduction in the use of inhaled rescue therapy and in the use of antibiotics and oral corticosteroids. The number of unscheduled physician visits was also significantly reduced with tiotropium treatment.

Exacerbation of COPD (complex of respiratory symptoms/events of $>3$ days' duration requiring a change in treatment) was a secondary endpoint in the SPRUCE study described previously. ${ }^{16}$ The proportion of patients experiencing one or more exacerbations was significantly reduced with tiotropium compared with placebo, independent of disease severity $(9.5 \%$ of those receiving tiotropium had $\geq 1$ exacerbation compared with $17.9 \%$ of the placebo group, $p=0.0147)$.

\section{Pulmonary rehabilitation}

Lung hyperinflation and reduced inspiratory capacity can significantly limit the duration of physical activity undertaken by patients with COPD. ${ }^{39}$ However, the sustained 24-hour bronchodilation afforded by tiotropium treatment translates into greater exercise tolerance and reduced lung hyperinflation in patients with COPD. ${ }^{35,36}$ Therefore, treatment with tiotropium has the potential to improve outcomes of patients engaging in pulmonary rehabilitation programmes. Pulmonary rehabilitation programmes are an effective intervention for patients with COPD and are becoming increasingly recognised as a component of standard COPD care.

One placebo-controlled study has shown that tiotropium treatment amplifies the benefits of pulmonary rehabilitation alone. ${ }^{40}$ This study followed 91 patients who participated in 8 weeks of pulmonary rehabilitation (the recommend duration of these programmes). Tiotropium or placebo was administered 5 weeks before engaging in the programme and was continued throughout the programme and for 12 weeks after its completion. The post-rehabilitation treatment period evaluated whether the benefits of pulmonary rehabilitation were better maintained with tiotropium than with placebo. Tiotropium in combination significantly improved patients' exercise endurance at the conclusion of the exercise programme compared with placebo, and these improvements were sustained 12 weeks after conclusion of pulmonary rehabilitation. The respective mean endurance exercise times (values expressed as tiotropium minus placebo) prior to pulmonary rehabilitation, at the end of 
pulmonary rehabilitation and 12 weeks after conclusion of the programme were 1.65 minutes $(p=0.183), 5.35$ minutes $(p=0.025)$ and 6.60 minutes $(p=0.018)$. Pulmonary rehabilitation induced improvements in exercise tolerance in both treatment groups, but the tiotropium group obtained significantly greater benefit. Tiotropium also produced clinically significant improvements in dyspnoea as determined by the transition dyspnoea index (TDI). Prior to pulmonary rehabilitation, the respective mean TDI focal scores were 1.75 and 0.91 for tiotropium and placebo $(p>0.05)$, but 12 weeks after completion of the programme the TDI score had declined in the placebo group but was maintained in the tiotropium group (1.75 vs $0.08 ; p<0.05)$. Health status (as determined by the SGRQ) was improved by a greater extent with tiotropium compared with placebo. Mean use of rescue salbutamol also declined in the tiotropium group.

\section{Treatment persistence}

Persistence with tiotropium therapy appears to be higher compared with other inhaled drugs that are widely used to manage COPD in clinical practice. ${ }^{41,42}$ Patients' persistence with tiotropium has been evaluated using a large database of drug-dispensing and hospital discharge records for 2 million patients in the Netherlands. ${ }^{41}$ About $37 \%$ of tiotropium-treated individuals persisted with tiotropium treatment for 1 year, compared with 14\% for ipratropium, 13\% for LABAs and $17 \%$ for combined LABA/inhaled corticosteroid treatment. In patients with a prior hospitalisation for COPD, 1-year persistence rates increased for all treatments, and increased to up to $61 \%$ for patients using tiotropium. A Canadian study of persistence with inhaled medications for COPD using prescription claims data reported generally low persistence with inhaled treatment, although more patients remained on tiotropium therapy for significantly longer compared with other medications. Thus, at 12 months, $53 \%$ of patients taking tiotropium remained on treatment with $7-30 \%$ remaining on treatment with other therapies (all comparisons $p<0.0001$ ). There were also fewer switches to alternative medications in the tiotropium group.

\section{SAFETY AND TOLERABILITY}

Tiotropium was generally well tolerated over the short- (13 weeks) and long-term (1 year), with a safety profile comparable with that of ipratropium (Table 1). ${ }^{15,18,21,22}$ No systemic adverse events were observed with the exception of an increased incidence of dry mouth, which occurred in approximately 14\% of patients, and which was generally mild in severity, resolved with continuing treatment and did not necessitate treatment discontinuation. ${ }^{13}$ A pooled analysis of adverse event data from 19 double-blind, placebo-controlled trials encompassing 4,435 tiotropium-treated patients and 3,384 placebotreated patients reported a higher relative risk (RR) of dry mouth in the tiotropium group (RR: 3.60; 95\% CI: 2.56-5.05).$^{43}$ However, tiotropium was associated with a lower risk of dyspnoea (RR: 0.64; 95\% CI: 0.50-0.81) and COPD exacerbations (RR: 0.72; 95\% CI: 0.64-0.82) compared with placebo. As discussed previously the low incidence of systemic adverse events associated with tiotropium treatment reflects the limited absorption of the drug through the respiratory and gastrointestinal mucosa. ${ }^{44}$

\section{PHARMACOECONOMICS}

The reduction in hospitalisations and exacerbations associated with tiotropium may translate into reduced consumption of healthcare resources which may offset the acquisition cost of the drug. Using data from clinical trials comparing tiotropium and ipratropium, Bandolier calculated that the number needed to treat (NNT) with tiotropium to prevent one patient from having at least one admission in a year was 25. ${ }^{22,40,45}$ Tiotropium treatment was 
Table 1. Incidence of adverse events (\%) with tiotropium reported in two clinical trials. ${ }^{15,21}$

\begin{tabular}{|c|c|c|c|c|}
\hline & \multicolumn{2}{|c|}{ Casaburi et al., $\mathbf{2 0 0 0}^{15}$} & \multicolumn{2}{|c|}{ Van Noord et al., $\mathbf{2 0 0 0}^{21}$} \\
\hline & Tiotropium & Placebo & Tiotropium & Ipratropium \\
\hline Any adverse event & 61.6 & 66.5 & 67.5 & 63.9 \\
\hline \multicolumn{5}{|l|}{ General } \\
\hline Chest pain & 3.2 & 1.6 & 2.6 & 0 \\
\hline Back pain & 2.5 & 3.1 & & - \\
\hline Fatigue & - & - & 2.1 & 1.0 \\
\hline Headache & 5.4 & 7.3 & 5.2 & 10.3 \\
\hline Influenza-like symptoms & - & - & 3.1 & 8.2 \\
\hline \multicolumn{5}{|l|}{ Nervous system } \\
\hline Dizziness & 3.2 & 3.7 & - & - \\
\hline Hypoaesthesia & 2.2 & 0 & - & - \\
\hline \multicolumn{5}{|l|}{ Gastrointestinal system } \\
\hline Abdominal pain & 9.3 & 0.5 & - & - \\
\hline Constipation & 2.9 & 1.0 & - & - \\
\hline Diarrhoea & 3.6 & 3.1 & - & - \\
\hline \multicolumn{5}{|l|}{ Upper respiratory system } \\
\hline Dry mouth & 9.3 & 1.6 & 14.7 & 10.3 \\
\hline Pharyngitis & 2.9 & 1.6 & 3.1 & 0 \\
\hline Sinusitis & 3.6 & 3.1 & - & - \\
\hline Upper respiratory tract infection & 15.8 & 15.2 & 18.3 & 11.3 \\
\hline \multicolumn{5}{|l|}{ Lower respiratory system } \\
\hline COPD exacerbation & 16.1 & 21.5 & 11.0 & 12.4 \\
\hline Cough & - & - & 2.6 & 5.2 \\
\hline Pneumonia & - & - & 2.6 & 2.1 \\
\hline
\end{tabular}

estimated to save at least 0.6 of a hospital day per year compared with an average number of hospital days of 1-2 for patients in control groups. ${ }^{45}$ Extrapolating these data to the entire UK population, tiotropium therapy could result in a potential net saving of 528,000 bed-days or the equivalent of four 400-bed hospitals. ${ }^{45}$ Pharmacoeconomic analyses of data from a yearlong study which compared tiotropium plus usual care with usual care alone, ${ }^{16}$ showed that the significant reduction in exacerbations, hospitalisations and days spent in hospital associated with the addition of tiotropium, translated into significant economic savings. ${ }^{46} \mathrm{~A}$ similar analysis reported that the number of hospital admissions, hospital days and unscheduled visits to healthcare providers was reduced by 46,42 and $36 \%$ in tiotropiumcompared with ipratropium-treated patients. ${ }^{47}$ 


\section{KEY POINTS}

- Tiotropium reduces bronchoconstriction and mucus hypersecretion via selective inhibition of the $M_{1}$ and $\mathrm{M}_{3}$ muscarinic receptors.

- Tiotropium provides sustained improvements in lung function, dyspnoea and exercise endurance and also reduces the need for inhaled rescue therapy. Health-related quality of life is also improved.

- Improvements in patient-centred outcomes (e.g. breathlessness on exertion) correlate with changes in inspiratory capacity and a reduction in lung hyperinflation.

- Tiotropium results in fewer exacerbations and hospitalisations, which may lead to substantial reductions in healthcare costs.

- Tiotropium is more effective than salmeterol. Emerging evidence suggests additive effects are achieved when tiotropium is combined with formoterol.

- Triple therapy with tiotropium and salmeterol/fluticasone propionate appears to improve lung function compared with tiotropium alone.

- Combining tiotropium with pulmonary rehabilitation results in significant improvements in exercise endurance.

- Tiotropium is generally well tolerated with a safety profile comparable with that of placebo and ipratropium. There is no evidence of tachypyhylaxis with longer term treatment.

\section{REFERENCES}

1 Lopez AD, Murray CC. The global burden of disease, 1990-2020. Nat Med 1998; 4: 1241-3.

2 World Health Organization.The World Health Report 2000. Health systems: Improving Performance. Geneva: WHO, 2000.

3 World Health Organization. Fact sheet. Chronic obstructive pulmonary disease (COPD). wrww.who.int/mediacentre/factsheets/fs315/en/index.html

4 Pauwels RA, Buist AS, Ma P et al. Global strategy for the diagnosis, management, and prevention of chronic obstructive pulmonary disease: National Heart, Lung, and Blood Institute and World Health Organization Global Initiative for Chronic Obstructive Lung Disease (GOLD): executive summary. Respir Care 2001; 46: 798-825.

5 Beeh KM, Welte T, Buhl R. Anticholinergics in the treatment of chronic obstructive pulmonary disease. Respiration 2002; 69: 372-9.

6 Maesen FP, Smeets JJ, Sledsens TJ et al. Tiotropium bromide, a new long-acting antimuscarinic bronchodilator: a pharmacodynamic study in patients with chronic obstructive pulmonary disease (COPD). Dutch Study Group. Eur Respir 7 1995; 8: 1506-13.

7 Disse B, Reichl R, Speck G et al. Ba 679 BR, a novel longacting anticholinergic bronchodilator. Life Sci 1993; 52: 537-44.

8 Haddad EB, Mak JC, Barnes PJ. Characterization of $[3 \mathrm{H}] \mathrm{Ba} 679 \mathrm{BR}$, a slowly dissociating muscarinic antagonist, in human lung: radioligand binding and autoradiographic mapping. Mol Pharmacol 1994; 45: 899-907.

9 Disse B, Speck GA, Rominger KL et al. Tiotropium (Spiriva): mechanistical considerations and clinical profile in obstructive lung disease. Life Sci 1999; 64: 457-64.
10 Disse B, Rominger KL, Serby CW et al. The pharmacokinetic (PK) profile of tiotropium during long-term treatment in stable COPD. Am 7 Respir Crit Care Med 1999; 159(3, Part 2): A524.

11 Boehringer Ingelheim Ltd. Spiriva ${ }^{\circledR}$ (tiotropium). Summary of product characteristics. Bracknell, Berkshire, 2004.

12 Turck D, Weber W, Sigmund R et al. Pharmacokinetics of intravenous, single-dose tiotropium in subjects with different degrees of renal impairment. 7 Clin Pharmacol 2004; 44: 163-72.

13 Olin JL. Tiotropium: an inhaled anticholinergic for chronic obstructive pulmonary disease. Am F Health Syst Pharm 2005; 62: 1263-9.

14 Somand H, Remington TL. Tiotropium: a bronchodilator for chronic obstructive pulmonary disease. Ann Pharmacother 2005; 39: 1467-75.

15 Casaburi R, Briggs DD, Donohue JF et al. The spirometric efficacy of once-daily dosing with tiotropium in stable COPD: a 13-week multicenter trial. The US Tiotropium Study Group. Chest 2000; 118: 1294-302.

16. Freeman D, Lee A, Price D. Efficacy and safety of tiotropium in COPD patients in primary care - the SPiRiva Usual CarE (SPRUCE) study. Resp Res 2007; 8: 45. available from http://respiratory-research.com/content/8/1/45

17. National Institute for Clinical Excellence. Chronic obstructive pulmonary disease - management of chronic obstructive pulmonary disease in adults in primary and secondary care. Clinical Guideline 12. London, 2004.

18 Casaburi R, Mahler DA, Jones PW et al. A long-term evaluation of once-daily inhaled tiotropium in chronic obstructive pulmonary disease. Eur Respir f 2002; 19: 217-24.

19 Calverley PM, A. AJ, Celli B et al. Salmeterol and fluticasone propionate and survival in chronic obstructive pulmonary disease. $\mathcal{N}$ Engl 7 Med 2007; 356: 775-89. 
20 Anzueto A, Tashkin D, Menjoge S, Kesten S. One-year analysis of longitudinal changes in spirometry in patients with COPD receiving tiotropium. Pulm Pharmacol Ther 2005; 18: 75-81.

21 van Noord JA, Bantje TA, Eland ME et al. A randomised controlled comparison of tiotropium and ipratropium in the treatment of chronic obstructive pulmonary disease. The Dutch Tiotropium Study Group. Thorax 2000; 55: 289-94.

22 Vincken W, van Noord JA, Greefhorst AP et al. Improved health outcomes in patients with COPD during 1 yr's treatment with tiotropium. Eur Respir f 2002; 19: 209-16.

23 Donohue JF, van Noord JA, Bateman ED et al. A 6-month, placebo-controlled study comparing lung function and health status changes in COPD patients treated with tiotropium or salmeterol. Chest 2002; 122: 47-55.

24 Tashkin DP. Is a long-acting inhaled bronchodilator the first agent to use in stable chronic obstructive pulmonary disease? Curr Opin Pulm Med 2005; 11: 121-8.

25 Briggs DD, Covelli H, Lapidus R et al. Improved daytime spirometric efficacy of tiotropium compared with salmeterol in patients with COPD. Pulm Pharmacol Ther 2005; 18: 397-404.

26 Brusasco V, Hodder R, Miravitlles M et al. Health outcomes following treatment for six months with once daily tiotropium compared with twice daily salmeterol in patients with COPD. Thorax 2003; 58: 399-404.

27 van Noord JA, Aumann JL, Janssens E et al. Comparison of tiotropium once daily, formoterol twice daily and both combined once daily in patients with COPD. Eur Respir 7 2005; 26: 214-22.

28. Seemungal T, Stockley R, Calverley $\mathrm{P}$ et al. Effect of salmeterol/fluticasone propionate versus tiotropium bromide on exacerbations: the INSPIRE study (investigating new standards for prophylaxis in reduction of exacerbations). Poster presented at the European Respiratory Society Annual Congress, Stockholm, Sweden 15-19 September 2007.

29. Stockley R, Calverley P, Seemungal T et al. Effect of salmeterol/fluticasone propionate versus tiotropium bromide on withdrawal rate, health status, lung function and mortality: INSPIRE (investigating new standards for prophylaxis in reduction of exacerbations). Oral presentation made at the European Respiratory Society Annual Congress, Stockholm, Sweden 15-19 September 2007.

30. Calverley P, Stockley R, Seemungal T et al. Adverse events and mortality in the INSPIRE study (investigating new standards for prophylaxis in reduction of exacerbations). Poster presented at the European Respiratory Society Annual Congress, Stockholm, Sweden 15-19 September 2007.

31. Singh D, Brooks J, Hagan G, O'Connor BJ. Superiority of the 'triple' therapy of salmeterol/fluticasone proprionate (SFG) and tiotropium (TIO) vs. individual components in COPD. Oral presentation made at the European Respiratory Society Annual Congress, Stockholm, Sweden 15-19 September 2007.

32. Aaron SD, Vandemheen KL, Fergusson D et al. for the Canadian Thoracic Society/Canadian Respiratory Clinical Research Consortium. Tiotropium in combination with placebo, salmeterol, or fluticasone-salmeterol for treatment of chronic obstructive pulmonary disease: a randomized trial. Ann Intern Med; 146: 545-555
33 Tashkin DP, Cooper CB. The role of long-acting bronchodilators in the management of stable COPD. Chest 2004; 125: 249-59.

34 Barr RG, Bourbeau J, Camargo CA, Ram FS. Inhaled tiotropium for stable chronic obstructive pulmonary disease. Cochrane Database Syst Rev 2005: CD002876.

35 O'Donnell DE, Fluge T, Gerken F et al. Effects of tiotropium on lung hyperinflation, dyspnoea and exercise tolerance in COPD. Eur Respir 7 2004; 23: 832-40.

36 Maltais F, Hamilton A, Marciniuk D et al. Improvements in symptom-limited exercise performance over $8 \mathrm{~h}$ with oncedaily tiotropium in patients with COPD. Chest 2005; 128: 1168-78.

37 Niewoehner DE, Rice K, Cote G et al. Prevention of exacerbations of chronic obstructive pulmonary disease with tiotropium, a once-daily inhaled anticholinergic bronchodilator: a randomized trial. Ann Intern Med 2005; 143: 317-26.

38 Dusser D, Bravo ML, Iacono P. The effect of tiotropium on exacerbations and airflow in patients with COPD. Eur Respir f 2006; 27: 547-55.

39 Lindsay M, Lee A, Chan K et al. Does pulmonary rehabilitation give additional benefit over tiotropium therapy in primary care management of chronic obstructive pulmonary disease? Randomized controlled clinical trial in Hong Kong Chinese. 7 Clin Pharm Ther 2005; 30: 567-73.

40 Casaburi R, Kukafka D, Cooper CB et al. Improvement in exercise tolerance with the combination of tiotropium and pulmonary rehabilitation in patients with COPD. Chest 2005; 127: 809-17.

41 Breekveldt-Postma NS, Koerselman J, Erkens JA et al. Enhanced persistence with tiotropium compared with other respiratory drugs in COPD. Respir Med 2007; 101: 1398-405.

42 Cramer JA, Bradley-Kennedy C, Scalera A. Treatment persistence and compliance with medications for chronic obstructive pulmonary disease. Can Respir f 2007; 14: 25-9.

43 Kesten S, Jara M, Wentworth C, Lanes S. Pooled clinical trial analysis of tiotropium safety. Chest 2006; 130: 1695-703.

44 Saberi F, O'Donnell DE. The role of tiotropium bromide, a long-acting anticholinergic bronchodilator, in the management of COPD. Treat Respir Med 2005; 4: 275-81.

$45 \mathrm{COPD}$ and treatment. Bandolier 9: 1-4.

46 Friedman M, Menjoge SS, Anton SF, Kesten S. Healthcare costs with tiotropium plus usual care versus usual care alone following 1 year of treatment in patients with chronic obstructive pulmonary disorder (COPD). Pharmacoeconomics 2004; 22: 741-9.

47 Oostenbrink JB, Rutten-van Molken MP, Al MJ, Van Noord JA, Vincken W. One-year cost-effectiveness of tiotropium versus ipratropium to treat chronic obstructive pulmonary disease. Eur Respir 7 2004; 23: 241-9.
Correspondence: Dr George Kassianos CSF Medical Communications Ltd, Eagle Tower, Montpellier Drive, Cheltenham, GL50 1TA, UK. Email: editor@csfmedical.com 